\title{
RESEARCH
}

\section{Politics and gender: rocking political science and creating new horizons}

\author{
PetraAhrens,Petra.Ahrens@uantwerpen.be \\ University of Antwerp, Belgium \\ Karen Celis, Karen.Celis@vub.be \\ Vrije Universiteit Brussel, Belgium \\ Sarah Childs,s.childs@bbk.ac.uk \\ Birkbeck, University of London, UK \\ Isabelle Engeli,I.Engeli@bath.ac.uk \\ University of Bath, UK \\ Elizabeth Evans, elizabeth.evans@gold.ac.uk \\ Goldsmiths, University of London, UK \\ Liza Mügge,L.M.Mugge@uva.nl \\ Universiteit van Amsterdam, Netherlands
}

key words feminism $\bullet$ gender $\bullet$ intersectionality $\bullet$ politics $\bullet$ privilege $\bullet$ sexuality

\section{Introduction}

We are immensely proud to launch the European Journal of Politics and Gender (EJPG). The EJPG is the flagship journal of the European Conference on Politics and Gender (ECPG). We founded this journal in the belief that gender is central to understanding politics: EJPG explores the multiple and interconnected dimensions that shape structures of power within politics. We are committed to publishing agenda-setting research on politics and gender that reflects the theoretical, methodological and epistemological diversity of the discipline. EJPG provides a space for dialogue across the broad spectrum of politics and gender research. It is the result of numerous conversations in which we, the founding editors, and others, identified the need for such an international journal. We are indebted to the pioneering work of political scientists in Europe and elsewhere, whose rigorous research and collective organising made sure that the study of politics and gender is no longer a sideshow. It has - in all its variety - become part of the discipline.

The EJPG is the natural next step of the activities of the growing political and gender community in Europe. The first milestone was the inception of a Standing Group 
on Women and Politics in the mid-1980s - later changed to Gender and Politics of the European Consortium for Political Research (ECPR). Under the leadership of Joni Lovenduski and Joyce Outshoorn, this group challenged the exclusion of women in the discipline and advocated the inclusion of gender as an analytical tool (Lovenduski, 2015). The second landmark was the organisation of the first ECPG at Queen's University, Belfast, in 2009 by Karen Celis and Johanna Kantola. Some of the other founding editors - Isabelle Engeli, Liza Mügge and Elizabeth Evans - later joined teams that organised subsequent ECPGs. The recent and highly successful development of the ECPG reflects the rapid expansion of the community and also marks the gradual shift from 'women and politics' to 'politics and gender'.

Over the past nine years, the ECPG has travelled across Europe to meet and engage with the politics and gender community. It has convened at the Central European University (2011), Pompeu Fabra University (2013), Uppsala University (2015) and the University of Lausanne (2017). The next ECPG will take place at the University of Amsterdam (4-6 July 2019). With its expansion, the ECPG has rapidly internationalised. Attendees are affiliated to institutions around the globe: ECPG 2017 counted participants working in more than 40 different countries across five continents. While the focus of the research community has always encompassed a broad-ranging definition of gender, over time, the ECPG has sought to be more inclusive, and explicitly so, by introducing sections on LGBTQI \{please spell out the abbreviation in full at first mention $\}$ and intersectionality. Together, ECPG scholarship is situated in a global debate on politics and gender. The EJPG pursues this international ambition further, and commits to publishing the best work on politics and gender irrespective of its geographical focus or the location of the author(s).

Notwithstanding the success of politics and gender research over the last few decades, bias against women and gender research very much remains in political science. Taking stock of the field, Isabelle Engeli, Elizabeth Evans and Liza Mügge convened a roundtable, 'Gender in Political Science Research: Achievement and Outlook', at the 2016 ECPR general conference. In this discussion, six renowned professors, men and women, gender and non-gender scholars, argued that collective efforts are needed to ensure that the wider discipline acknowledges and incorporates gender, as well as the insights of gender scholars. Visibility in publications is central to achieve this change. Yet, two problems arise. First, outlets to publish cutting-edge gender research in political science are scarce. Second, gender (and female) scholars are relatively invisible as 'mainstream' journals rarely publish beyond the traditional 'mainstream'. An ECPG special issue in European Political Science points to similar patterns in political science curriculums across Europe (Mügge et al, 2016). These findings fit the general, and growing, evidence of how political science is resistant to gendered change (Vickers, 2015). Women are published at lower rates than men in political science journals (Teele and Thelen, 2017), and 'manels' (all male panels) at political science events are still recurrent. The EJPG aims to support the community to address such issues of participation, dissemination and publication.

The EJPG provides a critical space in which politics and gender scholars can engage with key questions that underpin our study of political science. At the same time, the EJPG aims to disseminate politics and gender insights and analysis to the wider discipline, and beyond. The EJPG publishes research articles that are academically rigorous and innovative, make significant contributions to scholarly debates, and advance theoretical, empirical and methodological political analysis. In addition to 
research articles, the EJPG welcomes 'State of the Art' pieces, which provide timely analyses of theoretical, conceptual, methodological or empirical developments in the many sub-fields of politics and gender, and/or address the contributions of a diversity of politics and gender perspectives on a specific topic. These contributions focus on salient and contemporary issues and themes, exploring new research puzzles and dilemmas. Furthermore, we will provide a dedicated space to investigating specific questions in more depth and breadth by publishing an annual Special Issue selected through a competitive process.

At Bristol University Press the EJPG has found a publishing home, working in a human-scale environment that puts the promotion of academic work before profits. Publishing and copy-editing services [[It might be better to phrase this as Publishing is managed in-house as we use a UK freelancer who doesn't work for BUP but on behalf of?]] are done in-house with personalised services for the EJPG. We are thrilled to be going full speed into this new adventure for our community in partnership with Bristol University Press. Last but not least, we will promote our scholarship through the annual EJPG Best Paper Award. The prize will be awarded to the best article published in the EJPG in the previous year; it will be formally presented to the winner(s) at the following ECPG.

\title{
What's in a name? Our vision for 'politics' and 'gender' as a field of research
}

Our rationale for launching the EJPG is a conviction that a leading journal is needed to provide space for the extensive and varied innovative research that is conducted by scholars working in the politics and gender field. However, what do we mean by 'politics' and 'gender'? Interrogating these terms is vital, and our aim is to encourage articles that prompt new ways of thinking about and investigating both. Of course, neither term is politically neutral; they take on different meanings geographically and temporally. Exploring why we have selected these specific terms is therefore an important part of explaining our vision for the journal, as we highlight in our mission statement:

\begin{abstract}
EJPG is firmly embedded in global politics and gender scholarship, its scope is not limited to Europe.... EJPG understands gender as a political phenomenon that shapes power relations. Gender is contextual and is influenced by the intersection of multiple social categories and identities. These processes produce patterns of political inclusion and exclusion that are sometimes immediately visible, but often also hidden. EJPG therefore studies formal and informal components of politics in local, national, transnational and global realms.
\end{abstract}

We would like to take the opportunity here to unpack why we think the terms 'politics' and 'gender' are useful for theoretical and empirical analysis as part of a global debate. Moreover, we consider how intersectionality frames our approach, emphasise our commitment to sexuality research and reflect upon our positionality and privilege. 


\section{Politics}

Politics is about power, and power is gendered. We therefore adopt a wide-ranging definition of politics, one that encompasses both formal and informal processes and sites of contestation. 'The personal is political' is a powerful legacy from secondwave feminisms that makes explicit the connections between personal experience and political structures and power relations. The purpose of such a connection is to provide a framework to analyse the multiple ways in which gendered power dynamics are inextricably linked; this is a central part of politics and gender research. If politics is about power and about personal experiences, then politics is everywhere. We reject the depoliticising tendencies of some within political science to reduce politics to a neat set of formal institutions, and recognise the ways in which cultures, discourse and patterns of behaviour influence how, when, where and why women, men and those who identify as non-binary and gender-queer engage with and participate in political life broadly defined.

\section{Gender}

There is (still) much confusion surrounding the terms 'sex' and 'gender', and the two are often used interchangeably. While 'sex' typically refers to biological differences between males and females, gender is frequently taken to refer to a set of social constructions, which differ between societies, and that underpin a set of norms, cultures and behaviours that create and recreate asymmetric power dynamics between men and women, and between the 'masculine' and the 'feminine' - often to the detriment of the latter. This distinction has been much contested within feminism by those wary of viewing sex as somehow outside of the realm of the social. While acknowledging that definitions of gender differ, we believe that it shapes the life chances of everyone around the world. The use of gender as an analytical tool and framework can be understood as a normative approach, one that stresses the importance of differences between sex, race, culture, age and other identity markers. We readily acknowledge the critiques from post-colonial feminists regarding the dangers of ethnocentric approaches to categories often deployed within research on gender, such as 'woman' (Mohanty, 1992 \{citation not referenced, but see 1988. Please add/correct $\}$ ), and we are committed to engage with pluralistic and intersectional approaches to understanding gender. Although much of the research that emerges within the politics and gender field has women as its focus, we are keen to explore its effects upon men and those who identify as non-binary, gender-queer or intersex.

\section{Intersectionality}

We are committed to intersectionality as a political objective. Our approach to intersectionality is one that acknowledges and celebrates its roots within black feminism (Crenshaw, 1989 \{citation not referenced, but see 1991. Please add/ correct\}) as a means by which to explore the 'matrix of oppression' (Hill Collins, 1990) that can be found at the intersections of race and gender. In recent years, the term 'intersectionality' has been taken up by many gender scholars and activists to explore additional points of intersection, including, but not limited to, sexuality, 
class, religion and disability. We welcome work that centres race at the core of the intersectional perspective. As a framework, intersectionality makes visible the problematic homogenising terms 'women' (or likewise 'men'), 'gender' and '(in) equality', insisting on the need to explore the realities facing those who often remain at the margins of political discourse. Intersectionality, however, also allows studying the privileged: those in power and those that maintain structures of oppression.

\section{Sexuality}

The expansion of the ECPG to include research on sexuality has been an important development for the community in recent years. LGBTQI issues have reached global attention and political science has for too long been a laggard in the social sciences in acknowledging that sexual relations are a locus of power relations. Despite the increased attention to LGBTQI and sexuality, we recognise that research on gender and research on sexuality can still seem to talk past, rather than to, each other. At the same time, the EJPG hopes to contribute to the interrogation of sexuality in the discipline. Only then can we engage in cutting-edge analysis of power. It is our aim that scholars working on the politics of sexuality will find a welcoming home in the pages of the EJPG.

\section{Positionality and privilege}

Reflecting on our privilege is imperative. As politics and gender scholars, we are all too aware of the politics of exclusion that appear in both formal and informal institutions. Accordingly, we seek to avoid replicating parallel patterns of marginalisation in the EJPG. We are white European female scholars based at relatively wealthy institutions in leading higher education systems. The majority of ECPG attendants are similarly based at institutions that can financially support - at least partially - international mobility, such as attending conferences. Journal readership across disciplines can often be constrained by institutional capacity (and sometimes willingness) to subscribe to academic journals. Launching this journal affords us privilege and power in the knowledge-production process. In a career where publishing is vital, we, as journal editors, have a responsibility to ensure that we publish the very best research and do not engage in exclusionary publication practices. We will proactively seek out scholars from under-represented groups and encourage them to submit their work to our journal. We launch this journal in the spirit of an international community and hope that with the commitment of all, the EJPG will be of benefit to all.

\section{Politics and gender: creating new horizons}

As we outline in the EJPG Mission Statement, we aim to publish original research that spans the politics and gender field. This follows a commitment established by the ECPG to ensure that scholars working across a number of sub-fields are included. This reflects our desire to avoid recreating hegemonic patterns of inclusion and exclusion. We are keen to receive work that explores, but is not limited to, the following areas (in alphabetical order): advanced methods and techniques; citizenship; conflict and peace; development; elections; governance; international relations; LGBTQI politics; multilevel politics and the European Union; political economy; political 
representation; political theory; public policy; representation; security; and sexuality. These broad areas are often expected to 'speak for themselves'. We are keen for our authors to interrogate them in the coming years in order to develop new and crosscutting ways of analysing politics from a gendered perspective.

To launch the EJPG, we are publishing a double issue, giving prominence to a range of critical themes and questions that are foundational to our vision for the journal. The first issue showcases the diversity of politics and gender research across sub-fields that address wider concerns, and raise fundamental questions for politics and gender scholars, including knowledge production, normative epistemologies and power in the profession. The second issue addresses transversal opportunities, challenges, dilemmas and imperatives that cut across the various sub-fields and speak back to common research agendas within political science. Following a strict double-blind review process, we solicited articles from scholars working across the discipline and from different epistemological and methodological traditions. The authors reflect upon important contemporary research paradigms, highlight new areas of inquiry and engage with urgent and interrelated problems.

All of the articles included in our inaugural double issue set out future research agendas that we hope will be taken up in subsequent issues - creating multiple dialogues and wider conversations. Politics and gender is a rapidly increasing field of study, a field in which its scholars provide thorough and innovative analysis across all sub-disciplines of political science. The articles in this inaugural double issue mark, then, core aspects of where research started and where it should go in the future. As the inaugural issue went into production, and as a collective editorial team, we reflected on what we felt that this collection of articles tells us about the contemporary state of politics and gender 'out there'. Common themes prompt new thoughts on the development of our discipline, whether in terms of pivotal foci, enhancing the quality of our research and/or maximising the societal impact of our work. Before offering a brief introduction to the individual articles of the inaugural issue, let us first briefly sketch out two main themes that we feel are central in pushing further the horizon of politics and gender research at this moment.

\section{'Good' politics and gender research}

Most of the articles address, explicitly or implicitly, issues of intersectional inclusion and exclusion, the privileging and marginalising of fields of knowledge, and the relative status of particular research methodologies and data. In these pieces, there is an underlying critique of the generalist discipline of political science for its ongoing and unjust marginalisation and exclusion of knowledge produced by scholars in the fields of gender, sexuality and intersectionality. Too often, scholars are simply and straightforwardly excluded (for any number of reasons and by any number of means); other times, the process takes the subtler process of invisibilisation. Work and contributions are pushed aside, invalidated in some way or co-opted. Future articles in EJPG are encouraged to map, measure and theorise the actors and processes of exclusion and marginalisation, and to further develop the means by which rightful inclusion can be established. Scholars of colour, scholars based in the Global South and other minoritised groups have, for some time, critiqued the exclusionary practices within the research community, and they are right. In response, we - as a research community - should recognise privileges and act against any form of marginalisation 
and exclusion that we might reproduce. Only then will we produce 'good' gender and political science and 'good' gender and political scientists. The urgency is real both in and outside academia. Politics in 2018 is, across the globe, rife with overt and seemingly powerful resistance to principles of gender equality, to feminism, to LGBTQI rights and to anti-racism - in short, to the principles of equality, fairness and justice. In an era where the very notion of expert knowledge is under attack, the necessity to respond as a community of researchers has to be part of a wider counter-resistance to an insecure, unequal world.

\section{Transformative politics and gender research}

A great deal of attention across this inaugural issue focuses on global and international crises that generate and strengthen political projects of opposition and resistance to equality, seeking to protect the privileges of the powerful and the status quo. These crises set the context within which we, as a gender and politics community, undertake our research. They are also often the object of our research. For many politics and gender scholars, threats presented by conservatism, populism and authoritarianism, to name a few, constitute the research questions that drive us. Traditionally, of course, politics and gender research has long since been 'problem-driven'. Authors call attention to the question of change and transformation, and the role of academics in this process. While we refrain from speaking on the behalf of our authors, it is striking that many politics and gender scholars do not just criticise; rather, they offer ideas on how to transform gender relations and gendered power dynamics. This reminds us that politics and gender research is frequently a political act beyond, as well as within, the university. It is about engaging with equality, on the one hand, and resistance and opposition, on the other. Research can be for itself, but at other times, there may very well be an urgency for it to be more than this as well. To this end, the inaugural articles all point at the need for promoting diversity in research topics, analytical perspectives and methodologies. Our inaugural issue emphasises, then, the need for robust discussion of the conceptualisation and operationalisation of central concepts in politics and gender research - such as gender, equality or feminism. Successful discussion of this sort can only be promoted through methodological diversity, where quantitative research and more inductive research speak to each other, and through supporting the promotion of work located in or about the Global South and Central and Eastern Europe.

\section{Article overview}

Issue one: broadening the horizon of the politics and gender research agenda

As highlighted earlier, the EJPG is committed to intersectional research. However, what are the politics of knowledge production that underpin intersectional analysis? In 'Intersectionality and the politics of knowledge production', Liza Mügge, Celeste Montoya, Akwugo Emejulu and Laurel Weldon (2018) adopt a multi-methods approach to explore the various ways in which political scientists use intersectional frameworks. They trace the phenomenal development of the concept in political science, noting its 'increased popularity' among scholars since it first appeared in the 1980s. The authors highlight the importance of gender journals in publishing work 
on intersectionality, observing that it makes 'scant' appearances in mainstream political science journals. In order to analyse the use of intersectionality in political science research, the authors draw on an original, comprehensive database of political science articles on intersectionality, an analysis of the citation patterns and focus of these articles, and an online survey asking authors about their identity and approach to the study of intersectionality. The results show that the majority of respondents viewed intersectionality as a research paradigm and as a political project, thus reinforcing the normative assumptions at work in intersectionality research. Interrogating the definition of intersectionality, the authors note the importance of the scholar's social location and which intersections are prioritised. A citation analysis of published work on intersectionality revealed the virtual absence of non-US women of colour from reference lists, raising important questions of knowledge production and privilege.

In 'Power, knowledge and the politics of gender in the Global South', Peace Medie and Alice Kang (2018) explore the extent to which the study of women, gender and politics takes account of global power dynamics. The authors point to a 'truncated approach' that limits the majority of analyses to one where the global order is generally discussed as advantageous while 'the antithesis has remained understudied'. Moreover, not enough attention is paid to the interaction between colonialism, imperialism, capitalism, neoliberalism and globalisation, and their effects on gendered inequalities in the Global South. Medie and Kang recommend thinking more explicitly about the ways in which the global order affects the phenomenon under study, thereby highlighting the importance of context for addressing common research agendas. In the second part of their analysis, the authors analysed six journals, four from the Global North and two African journals, to find out the extent to which South-based scholars are represented. They find that Africa-based journals are more inclusive than their Northern counterparts and that scholars based in the Global South are severely under-represented in journals published in the Global North. Medie and Kang argue that informal networks privilege scholars in the Global North and there is a strong need to encourage scholars based in the Global South to submit their work for publication.

In 'Coming out of the political science closet: the study of LGBT politics in Europe', David Paternotte (2018) continues the exploration of marginalisation and exclusion, this time with a focus on the study of LGBT politics in Europe. Joining Medie and Kang in their critique of ethnocentric and whiteness bias in the discipline, Paternotte calls attention to one other bias of the field: the heterocentric bias. He argues that the growing political attention to LGBT issues has helped to break through the quite conservative door of political science and make sexual politics a legitimate object of study. Providing an account of epistemological and ontological hierarchies within the discipline, the author lays bare the 'implicit heteronormativity, transphobia and homophobia in political science'. Paternotte outlines the development of the subfield, noting the juxtaposition between its increasing popularity and the precarious nature of research networks and the careers of those academics who choose to focus on this area. The author argues that accepted categories and analytical tools should not prevent scholars from interrogating the extent to which they reinforce patterns of exclusion, highlighting in particular the dearth of research exploring intersex and bisexualism. Paternotte raises fundamental questions regarding the subject matter of research and the danger of relying on traditional categories that may further entrench patterns of marginalisation. 
Questioning hegemonic discourse and analytical categories is an issue that Elisabeth Prügl and J. Ann Tickner (2018) grapple with in their exploration of feminist International Relations (IR). In 'Feminist International Relations: some research agendas for a world in transition', they note the links between feminist IR and the feminist movement, but caution that alongside recognition of feminism's liberating and emancipatory potential, we must also recognise its potential dark side. They argue that feminist IR must challenge 'seemingly unproblematic concepts and framing works' while continuing to ask feminist questions. The authors revisit feminist security studies and the global political economy as sub-fields of feminist IR to highlight current research agendas. Although Prügl and Tickner acknowledge the dominance of post-positivism within the field, they also observe increasing methodological diversity. They call for more micro-level empirical research, for instance, to explore the gendered politics that motivate violence and war. Furthermore, the authors herald the potential for queer analysis to recast research puzzles at the heart of mainstream security studies and gendered political economy.

Critiquing mainstream research and developing alternative analytical frameworks has also been a key priority for feminist political economists and welfare state scholars. In 'Gendering welfare state analysis: tensions between care and paid work', Rossella Ciccia and Diane Sainsbury (2018) review the decades of gendering comparative welfare state analysis through the lens of the division between paid work and care. They show that care is still too often viewed as subordinate to paid employment in mainstream analyses despite the enormous influence of feminist theorising on conceptions of the welfare state, while feminist research still struggles to provide a balanced account of both paid and care work. Ciccia and Sainsbury argue that overcoming the tension between paid and care work is of vital importance to fully incorporating gender in welfare state analysis, together with the need to adopt new analytical approaches that address intersectionality, immigration and long-term perspectives of welfare state change.

How we evaluate the impact of policy implementation on gender transformation is the issue taken up in 'Taking implementation seriously in assessing success: the politics of gender equality policy'. Isabelle Engeli and Amy G. Mazur (2018) propose a new approach to assess how governments can achieve gender equality in practice. The authors call for the systematic examination of the politics of the implementation process, as well as the need for impact evaluations as a means by which to better understand the myriad challenges to realising gender and sexual equality. Engeli and Mazur note the increased number of global indicators for gender equality but argue that the objective of those seeking to understand gender-equality policies should not simply be to rank countries, but to understand why some countries are more or less successful in implementing the policies than others. The authors call for scholars to go beyond 'static' quantitative approaches in order to better focus on contextual post-adoption stages. This, they argue, would necessarily involve the investigation of the policy instruments and the empowerment process to assess the resulting policy outcomes. In adopting a new Gender Equality in Practice Approach, the authors' aim is not only to improve our understanding of what works and why, but also to help scholars provide a more nuanced and contextual analysis of policy outcomes to be conceived as shades of grey towards the ultimate goal of gender transformation that would break apart gender and sexual hierarchies of power. 
In understanding the persistence of gender inequality, Suzanne Dovi's (2018) 'Misogyny and transformation' explores the connection between misogyny and transformation, and, in particular, the ways in which the (limited) choices that women make are structured in such a way that their subordinate status is continually reconfirmed. The author calls for a re-conceptualisation of the connection between transformation and misogyny through a focus on a 'double bind', one that allows us to evaluate the extent to which women in politics can advance but only at a price, for instance, by aligning themselves with 'the powerful and privileged'. Dovi identifies four faces of misogyny (silencing, objectification, stereotyping and devaluation), each of which, she argues, is used as a mechanism to reinforce women's marginalisation. While the choices that women in politics can make are undeniably limited, Dovi calls for political science to pay greater attention to the distribution of 'rewards and punishments for different women'; such an intersectional analysis necessarily exposes the ways in which women can be hurt by misogyny, either through perpetuation or resistance.

Resistance to gender equality is further explored by Karen Celis and Joni Lovenduski (2018) in 'Power struggles: gender equality in political representation'. They argue that gendered and intersectional inequality in political representation should not only be understood through contextual factors or as a result of lacking feminist strategies, but also as a set of power struggles between feminist critical actors and their opponents. The authors argue that in order to understand such power struggles, scholars need to engage more explicitly with conceptions of power and resistance as enacted by different actors throughout the representation process. Drawing upon extant scholarship, Celis and Lovenduski delineate between active and positional power as the aims and means of the feminist strategies for improving gender equality in political representation; this, the authors note, could lead to a 'retheorisation of the resistance that is triggered by feminist power strategies'. Understanding more about resistance, in particular, how and why male over-representation is so successfully sustained, is a critical step in enabling scholars to analyse the power struggle itself and how we can better improve the success of feminist strategies for change.

\section{Issue two: pushing the boundaries in politics and gender: transversal approaches}

Interdisciplinarity is one of the hallmarks of politics and gender research, with scholars adopting and adapting theories, concepts and methods from beyond the discipline of political science. Many new research questions cannot be categorised in the traditional sub-fields, partly due to the diversity of academic backgrounds of those who do politics and gender research. This diversity helps push the boundaries of the field and we want the second issue of the EJPG to serve as an opportunity for learning from each other and for offering new ideas and new ways of approaching old and new research questions.

Georgina Waylen's (2018) 'Nudges for gender equality? What can behaviour change offer gender and politics?' makes the case for politics and gender to critically engage with behavioural change, more commonly known as nudge economics, an approach most closely associated with economics and psychology. Noting the tradition of pluralism and heterodoxy within politics and gender research, the author calls for a critical engagement with an approach that has, to date, been gender-blind in order to better help us understand policymaking. Behavioural change typically relies upon 
experimental methods, in particular, randomised control tests, an approach that Waylen notes can be viewed as inappropriate by politics and gender researchers. However, the author suggests that making use of such methods in conjunction with traditional methodological approaches, such as observational data and qualitative research, can enable politics and gender scholars to more confidently make claims regarding the efficacy of specific interventions in challenging and changing gender norms.

The impact that feminist scholars can have upon behavioural and institutional change is a subject taken up by Sarah Childs and Drude Dahlerup (2018). 'Increasing women's descriptive representation in national parliaments: the involvement and impact of gender and politics scholars' reflects upon the challenges and opportunities for enhancing descriptive representation. While the descriptive representation of women is central to politics and gender research, the role of scholars in the process of influencing change has attracted little attention. The authors argue that there is a need to conceptualise the activities undertaken by academic actors, such as shaping public debate or advising political parties and political institutions, in order to better understand the 'opportunities and resistance' that scholars, as 'academic change actors', might need to negotiate. Drawing upon their own experience, Childs and Dahlerup highlight how politics and gender scholars who seek to impact the debate surrounding women in politics face a series of challenges, such as a lack of resources, forging alliances, the risk of co-option, expectations and resistances. Despite these obstacles, the authors argue that politics and gender scholars have both directly and indirectly contributed towards the increased descriptive representation of women in politics.

How politics and gender researchers conceptualise gender equality is the central question posed by Johanna Kantola and Mieke Verloo (2018) in 'Revisiting gender equality at times of recession: a discussion of gender and politics scholarship's strategies of dealing with equality'. Kantola and Verloo argue that in the current context of neoliberalism and the ongoing legacy of the 2008 financial crisis, greater critical reflection on the concept is required. The authors highlight four predominant strategies that politics and gender scholars typically employ when discussing gender equality - escaping equality, fixing equality, deconstructing equality and delegating equality to political theory - arguing that scholars should more explicitly reflect upon their particular approach. Such critical engagement would, Kantola and Verloo argue, help us move beyond proving 'over and over again what we already know, and what is already substantially proven: that the world is gendered and that there is still gender inequality'. More precision is needed in the use of the concept of equality to enable a stronger cumulative debate on gender equality that links feminist normative theory and empirical research.

Centring neoliberalism, Catherine Eschle and Bice Maiguashca (2018), in 'Theorising feminist organising in and against neoliberalism: beyond co-optation and resistance?', explore the co-optation and resistance dichotomy within academic debates about feminist activism in neoliberal contexts. They identify three narratives: a high-profile 'strong' co-optation thesis; a more nuanced co-optation discourse; and an emergent counter-narrative of resistance. In this, the authors criticise the 'monolithic' and 'totalising' accounts of feminism that position it as a project wholly co-opted by neoliberalism, as well as the too-readily-ceded feminist label in favour of 'market feminism' or 'transnational business feminism'. In particular, they examine the ways in which we might think differently about the 'who' and 'where' of feminism 
within neoliberal contexts. Here, they are critical of depictions of the 'good girls' and 'bad girls' of feminism, and of a juxtaposition between institutional politics and grassroots activism. In better understanding feminist mobilisation and activism, Eschle and Maiguashca contend that feminism should be re-conceptualised as a collective, leftist struggle that is, hence, incompatible with neoliberalism and its eschewal of equality and egalitarianism.

Of course, it is not only agency and resistance that is political; the methods and methodologies that we adopt as researchers are inherently political, and therefore gendered. Aili Mari Tripp and Melanie Hughes's (2018) 'Methods, methodologies and epistemologies in the study of gender and politics' charts the development of methods within the field, as well as the ongoing debates concerning the appropriateness of specific techniques for analysing gender, with a focus on developments in the US literature. The authors observe the traditional dominance of quantitative methods in political science, an approach typically associated with men, with women more likely than men to publish work that draws upon qualitative methods. This is problematic because the bias among generalist political science journals in favour of publishing quantitative research persists. While they note the 'quantitative turn' in empirical research on politics and gender research, Tripp and Hughes shed light on the growing sophistication of qualitative research in politics and gender and the need to overcome the difficulty in obtaining intersectional data, an issue that requires urgent attention in order to address important political questions. The development of mixed-methods research that draws on the strengths of both quantitative and qualitative approaches has allowed for innovative research in politics and gender.

Underpinning the choices that we make about methods are, at times, normative positions and ideological commitments. Jacqui True and Brooke Ackerly (2018), in 'With or without feminism? Researching politics and gender in the 21st century', argue for the importance of feminist methodology to researchers analysing politics and gender. The authors call for a commitment to feminism, one that requires researchers to be self-consciously normatively committed to gender and other inequalities in order to 'reveal and take on the power inequalities in academic research and in society that render gender inequality invisible'. True and Ackerly distinguish between feminist and non-feminist research, noting that feminist research aims to transform gender relations, while non-feminist approaches may have no discernible interest in influencing the political agenda. They observe the links between theoretical and empirical accounts of gender: where theory can help us understand what it means to treat women as people and why that idea is so radical, empirical analysis considers what people have done and can do to transform gender dynamics such that women are treated as people too. The link between theory and empirics is therefore critical to feminist research in order to change gender relations.

The final article addresses the marginalisation of women in political science. Amy L. Atchison (2018) provides a sobering read in 'Towards the good profession: improving the status of women in political science': women political scientists are more likely to hold precarious positions and are less likely to be found among the senior ranks; women are less likely to be published, especially in the top-ranked journals; women are less likely to be cited than men; and women are excluded from male networks. The author observes that intersectional analysis would likely reveal further patterns of marginalisation, especially for women of colour, but such data are not available to study. The author argues that we must understand the full extent of marginalisation, 
including the links between gender and race, in order to fully develop strategies for improving the status of women and tackling the 'structural inequalities' within political science.

We would like to close with expressing our appreciation to three groups of people without whom this launch issue would never have been brought to life. First, the Editorial Board for their hard work and support in helping us develop and launch this journal. Made up of distinguished scholars from around the world, our board represents the various sub-fields of political science in all its diversity, as well as the full range of methodological approaches and epistemological positions. Second, we express our immense gratitude to our reviewers, who worked under the tightest of deadlines and yet offered hugely insightful reviews to ensure that this launch issue is of the highest standard. We acknowledge their good grace. Third, our thanks must go to our authors and readers - past, present and future. We hope you will enjoy this new journey for the politics and gender community as much as we do. Let's rock the political science show.

\section{References}

Atchison, AL, 2018, Towards the good profession: improving the status of women in political science, European Journal of Politics and Gender, 1, 2, pp \#pages\#

Celis, K, Lovenduski, J, 2018, Power struggles: gender equality in political representation, European Journal of Politics and Gender, 1, 1, pp \#pages\#

Childs, S, Dahlerup, D, 2018, Increasing women's descriptive representation in national parliaments: the involvement and impact of gender and politics scholars, European Journal of Politics and Gender, 1, 2, pp \#pages\#

Ciccia, R, Sainsbury, D, 2018, Gendering welfare state analysis: tensions between care and paid work, European Journal of Politics and Gender, 1, 1, pp \#pages\#

\{Reference not cited, but see 1989. Please cite/correct/delete as appropriate\} Crenshaw, K, 1991, Mapping the margins: intersectionality, identity politics, and violence against women of color, Stanford Law Review, 43, 6, 1241-99

Dovi, S, 2018, Misogyny and transformation, European Journal of Politics and Gender, 1, 1, pp \#pages\#

Engeli, I, Mazur, AG, 2018, Taking implementation seriously in assessing success: the politics of gender equality policy, European Journal of Politics and Gender, 1, 1, pp \#pages\#

Eschle, C, Maiguashca, B, 2018, Theorising feminist organising in and against neoliberalism: beyond co-optation and resistance?, European Journal of Politics and Gender, 1, 2, pp \#pages\#

Hill Collins, P, 1990, Black feminist thought: Knowledge, consciousness, and the politics of empowerment, Boston, MA: Unwin Hyman

Kantola, J, Verloo, M, 2018, Revisiting gender equality at times of recession: a discussion of gender and politics scholarship's strategies of dealing with equality, European Journal of Politics and Gender, 1, 2, pp \#pages\#

Lovenduski, J, 2015, Gendering politics: Feminising political science, Colchester: ECPR Press

Medie, P, Kang, A, 2018, Power, knowledge, and the politics of gender in the Global South, European Journal of Politics and Gender, 1, 1, pp \#pages\# 
\{Reference not cited, but see 1992. Please cite/correct/delete as appropriate\} Mohanty, CT, 1988, Under Western eyes: feminist scholarship and colonial discourses, Feminist Review, 30, 61-88

Mügge, L, Evans, E, Engeli, I, 2016, Introduction: gender in European political science education - taking stock and future directions, European Political Science, 15, 3, 281-91

Mügge, LM, Montoya, C, Emejulu, A, Weldon, L, 2018, Intersectionality and the politics of knowledge production, European Journal of Politics and Gender, 1, 1, \#pages\#

Paternotte, D, 2018, Coming out of the political science closet: the study of LGBT politics in Europe, European Journal of Politics and Gender, 1, 1, \#pages\#

Prügl, E, Tickner, JA, 2018, Feminist International Relations: some research agendas for a world in transition, European Journal of Politics and Gender, 1, 1, \#pages\#

Teele, DL, Thelen, K, 2017, Gender in the journals: publication patterns in political science, PS: Political Science \& Politics, 50, 2, 433-47

Tripp, AM, Hughes, M, 2018, Methods, methodologies, and epistemologies in the study of gender and politics, European Journal of Politics and Gender, 1, 2, pp \#pages\#

True, J, Ackerly, B, 2018, With or without feminism? Researching politics and gender in the 21st century, European Journal of Politics and Gender, 1, 2, pp \#pages\#

Vickers, J, 2015, Can we change how political science thinks? 'Gender mainstreaming' in a resistant discipline, Canadian Journal of Political Science, 48, 4, 1-24

Waylen, G, 2018, Nudges for gender equality? What can behaviour change offer gender and politics?, European Journal of Politics and Gender, 1, 2, pp \#pages\#

\section{Page ranges will be added once the articles are re-paginated}

